\title{
OXIGÊNIO NO CONTEXTO DA COVID-19: O QUE SABEMOS SOBRE A MOLÉCULA QUE RESPIRAMOS E O
} PAPEL CENTRAL DA QUÍMICA

\author{
Bruna C. Cerqueira ${ }^{a}$, Bruna Reis Silva ${ }^{b}$, Rafael Camposa, Lourenço Luis Botelho de Santana ${ }^{\mathrm{b}}$, Wilson Araújo Lopes ${ }^{\mathrm{a}, \mathrm{c}}$, \\ Luciana A. Silva ${ }^{\mathrm{a}, \mathrm{c}}$, Rodrigo De Paula ${ }^{\mathrm{d}, \mathrm{e}}$ e Silvio Cunha ${ }^{\mathrm{a}, \mathrm{c}, *,(\mathbb{D})}$ \\ anstituto de Química, Universidade Federal da Bahia, 40170-115 Salvador - BA, Brasil \\ ${ }^{b}$ Departamento de Ciências da Vida, Universidade do Estado da Bahia, 41195-000 Salvador - BA, Brasil \\ 'Instituto Nacional de Ciência e Tecnologia de Energia e Ambiente, Universidade Federal da Bahia, 40170-290 Salvador - BA, Brasil \\ ${ }^{d}$ Centro de Formação de Professores, Universidade Federal do Recôncavo da Bahia, 45300-000 Amargosa - BA, Brasil \\ eUniversidade Federal do Oeste da Bahia, 47810-059 Barreiras - BA, Brasil
}

Recebido em 21/04/2021; aceito em 22/06/2021; publicado na web em 08/07/2021

\begin{abstract}
OXYGEN IN THE COVID-19 CONTEXT: WHAT WE KNOW ABOUT THE MOLECULE WE BREATHE AND THE CENTRAL ROLE OF CHEMISTRY. In this work, the role of chemistry in the coronavirus disease 2019 (COVID-19) pandemic is highlighted through the medical oxygen supply crises in Brazil, as an example of oxygen utility in health. Starting from oxygen chemical characterization, the oxygen cycle in nature is discussed to show how oxygen is formed through photosynthesis, followed by the description of the industrial oxygen production from atmospheric air, including physical-chemical aspects. The use of medical oxygen concentrator is presented and how this device works from the chemical point of view. Besides, the noninvasive and painless oximetry is described in terms of how oxygen saturation level in blood is measured using LED - light emitting diode.
\end{abstract}

Keywords: medical oxygen; oxygen production; oximetry; oxygen chemical properties.

\section{INTRODUÇÃO}

Ciência! Vivemos tempos em que essa palavra está intensamente presente nas mídias, nos discursos dos políticos e em conversas cotidianas, em função da pandemia da COVID-19 provocada pelo vírus SARS-CoV-2. Inimaginável que aqui apareceria uma mutação do vírus altamente infectante e que o Brasil se tornaria, no início do ano 2021, no epicentro da doença, bem como que a defesa de se seguir os preceitos da ciência no enfrentamento à pandemia se tornaria tão necessário em pleno século XXI.

Se, por um lado, as medidas para mitigar o contágio do vírus e o tratamento hospitalar da COVID-19 com a necessidade de intubação nos casos mais graves se tornaram bem conhecidas por muitos, por outro lado, a recente e aguda crise de falta de oxigênio hospitalar em algumas cidades e estados, amplamente noticiada e com o ainda atual risco de desabastecimento nacional, Figura 1, revelaram que o público em geral não se atém à forma como as substâncias químicas são produzidas ou mesmo suas propriedades, bem como onde são produzidas e distribuídas pelo país, mesmo sendo tão comuns e vitais, como a substância oxigênio para uso hospitalar.

Em dezembro de 2020 a escassez de oxigênio no Brasil atingiu, principalmente, os estados do norte e nordeste do país. Como consequência, as indústrias ampliaram a produção de oxigênio medicinal em até $200 \%{ }^{13}$ e a ANVISA - Agência Nacional de Vigilância Sanitária - disponibilizou dados de produção, envase e distribuição de oxigênio medicinal em todo o país. ${ }^{14}$

Dado o desequilíbrio de produção e acesso ao insumo, pois a maior produção de oxigênio está situada no estado de São Paulo,
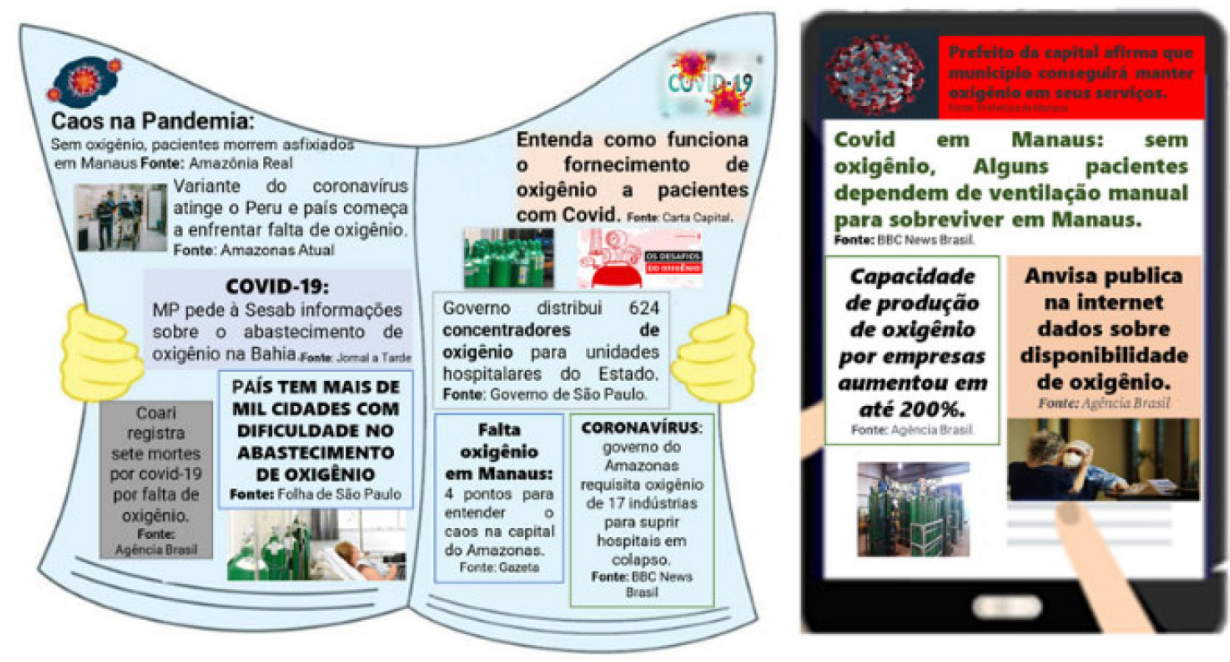

Figura 1. Notícias em mídias impressas ${ }^{1-8}$ e hipertextos ${ }^{9-12}$ sobre a falta de oxigênio medicinal 
seguida por Minas Gerais e Rio de Janeiro, ${ }^{14} \mathrm{o}$ "Plano Oxigênio Brasil" foi instaurado pelo Ministério da Saúde, com objetivo de auxiliar os estados e municípios no abastecimento com oxigênio medicinal durante a pandemia da COVID-19. ${ }^{15,16}$ Assim, a Medida Provisória 1.033/21 da Presidência da República ${ }^{17}$ dispensa as empresas produtoras de oxigênio medicinal, localizadas em zonas de processamento de exportação, de ter $80 \%$ de seu faturamento anual com vendas para o mercado externo, como determina a Lei $11.508 / 07.4,18$

Esse cenário trouxe a molécula do oxigênio - $\mathrm{O}_{2}$ - para o centro das preocupações da nossa sociedade e desponta como oportunidade de intensificarmos ações de divulgação científica.

A falta da molécula de $\mathrm{O}_{2}$ nos leva à morte. Num triste exemplo longe dos hospitais, mas que traduz a agonia da morte por falta de ar, há a imagem do afro-americano George Floyd sendo brutalmente sufocado por um policial, que correu mundo, com a sua frase I can't breathe pronunciada mais de vinte vezes durante o episódio. ${ }^{3}$ Quantos brasileiros acometidos pela COVID-19 e não assistidos adequadamente, portanto submetidos a um outro tipo de violência, pronunciaram ou pronunciarão a mesma frase agonizante "eu não consigo respirar" por causa da crise de abastecimento nacional de $\mathrm{O}_{2}$ ?

A Assembleia Geral das Nações Unidas proclamou 2019 como o Ano Internacional da Tabela Periódica dos Elementos Químicos (International Year of the Periodic Table of Chemical Elements - IYPT 2019). ${ }^{19}$ Deste então, muitas publicações descrevem a produção, aplicações e propriedades de elementos da Tabela Periódica e, em um número especial, a Química Nova contribuiu para a descrição de alguns produzidos no Brasil, especialmente os que são economicamente estratégicos como fonte de divisas para a nação..$^{20,21}$ Naturalmente, por esse aspecto, o oxigênio não foi contemplado, o que nem de longe significa que ter sua produção disseminada por todo país não é estratégico do ponto de vista de saúde pública.

Apresentamos aqui a sistematização de uma série de informações técnicas e científicas sobre o oxigênio, tais como produção industrial e emprego em saúde, e como se dá a mensuração da sua concentração na corrente sanguínea, procurando assim contribuir para a melhor compreensão do tema, proporcionando mais conhecimento geral sobre o oxigênio no contexto da COVID-19, somando-se ao empenho da comunidade química brasileira na disseminação de informações científicas no âmbito da pandemia, em particular sobre a molécula que respiramos..$^{22,23}$

\section{ASPECTOS GERAIS SOBRE O OXIGÊNIO}

Oxigênio é o primeiro elemento do Grupo $16(Z=8)$ e localiza-se no segundo período da Tabela Periódica, Figura 2. Oxigênio molecular ocorre em duas formas alotrópicas, o oxigênio que respiramos $\mathrm{O}_{2} \mathrm{e}$ o ozônio $\mathrm{O}_{3}$ presente, por exemplo, nos ozonizadores domésticos de desinfecção de água e popular no noticiário em função da destruição da camada de ozônio da atmosfera. ${ }^{24}$ As duas substâncias são gases no estado padrão, sendo a molécula diatômica $\left(\mathrm{O}_{2}\right)$ a forma termodinamicamente mais estável (Equação 1). ${ }^{25} \mathrm{~A}$ molécula de $\mathrm{O}_{2}$ pode ser denominada também como dioxigênio. Contudo, neste trabalho, daremos preferência à denominação oxigênio ao nos referimos a ela.

$2 \mathrm{O}_{3} \rightarrow 3 \mathrm{O}_{2} ; \quad \Delta \mathrm{G}^{\mathrm{o}}=-163 \mathrm{~kJ} \mathrm{~mol}^{-1}$

Paradoxalmente à crise de abastecimento nacional de $\mathrm{O}_{2}$ hospitalar, o elemento oxigênio figura como o mais abundante da Terra, presente em quantidades apreciáveis nos três compartimentos do nosso planeta. Na litosfera, está presente em todos os minerais silicatos e óxidos, respondendo por $46 \%$ da sua composição em massa.

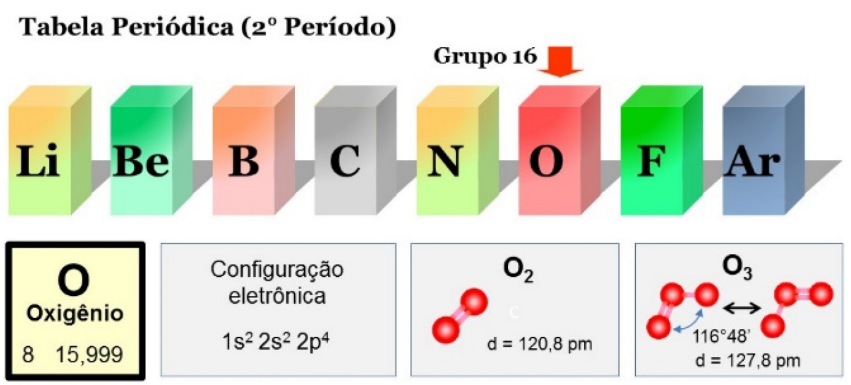

Figura 2. Informações sobre o elemento oxigênio e formas alotrópicas moleculares dos gases oxigênio $\mathrm{O}_{2}$ e ozônio $\mathrm{O}_{3}$

$\mathrm{Na}$ hidrosfera, é constituinte da água que está presente em mais de $70 \%$ da superfície do globo, respondendo por $85,8 \%$ da massa dos oceanos e $88,81 \%$ da massa de água doce. Na atmosfera está presente na forma de moléculas diatômicas $\left(\mathrm{O}_{2}\right)$ e corresponde a $23 \%$ em massa (cerca de $1,185 \times 10^{15}$ ton) e $20,9 \%$ em volume de todos os gases que compõem a troposfera, excluindo-se o vapor d'água. Além disso, encontra-se na forma de moléculas triatômicas $\left(\mathrm{O}_{3}\right)$ em quantidade variável estimada em cerca de 3,3 x $10^{9}$ ton, compondo a camada que filtra parte da radiação UV localizada na estratosfera, conhecida como camada de ozônio. ${ }^{26}$ Embora essa composição se mantenha quase constante, visto que o planeta é considerado um sistema fechado em termos de fluxos de massa, as interações entre os três compartimentos são contínuas e o oxigênio participa ativamente dos processos físicos, químicos e biológicos que envolvem grandes ciclos biogeoquímicos, tornando o planeta um sistema autossustentado e em evolução, Figura $3 .{ }^{27}$

A descoberta do oxigênio ocorreu entre os anos de 1772 e 1774 , mas quem o descobriu é alvo de debates até hoje. ${ }^{28} \mathrm{O}$ sueco C. W. Scheele e o inglês J. Priestley, de forma independente, foram os primeiros a produzir o oxigênio, mas foi A. L. Lavoisier quem explicou o seu papel na combustão, levando à queda da Teoria do Flogístico e a criação da Química moderna. O nome oxigênio dado por Lavoisier tem origem grega e significa formador de ácido, por acreditar que todos os ácidos eram substâncias oxigenadas. Só depois constatou-se que o oxigênio não é um elemento essencial aos ácidos, mas o nome já estava estabelecido e assim permaneceu.

Embora seja uma espécie com número par de elétrons, o $\mathrm{O}_{2}$ é paramagnético, isso é, possui elétrons desemparelhados e por isso sofre influência de um campo magnético externo. A Teoria do Orbital Molecular é bem-sucedida na explicação dessa propriedade. $\mathrm{O}$ diagrama dos níveis de energia da molécula de $\mathrm{O}_{2}$ na Figura 4 indica que dois elétrons ocupam orbitais moleculares antiligantes duplamente degenerados de simetria $\pi$ com spins paralelos, resultando no estado fundamental triplete, ${ }^{3} \Sigma_{\mathrm{g}}^{-}$, e ordem de ligação igual a 2 , conferindo elevada estabilidade à molécula (energia de ligação de $495 \mathrm{~kJ} \mathrm{~mol}^{-1}$ ). Há ainda dois possíveis estados excitados singlete: ${ }^{1} \Delta_{\mathrm{g}}$, se os dois elétrons ocuparem o mesmo orbital com spins antiparalelos $\mathrm{e}^{1} \Sigma_{\mathrm{g}}^{+}$, se os elétrons permanecerem desemparelhados, mas com spins antiparalelos. A energia do primeiro estado excitado singlete $\left({ }^{1} \Delta_{\mathrm{g}}\right)$ é de $94,72 \mathrm{~kJ} \mathrm{~mol}^{-1}$ acima do estado fundamental, enquanto a do segundo estado excitado singlete $\left({ }^{1} \Sigma_{\mathrm{g}}^{+}\right.$) é de $157,85 \mathrm{~kJ} \mathrm{~mol}^{-1}$ (Figura 4). ${ }^{14,16}$

$\mathrm{O}$ oxigênio molecular $-\mathrm{O}_{2}$ - condensa a $-183^{\circ} \mathrm{C}$ (a $1 \mathrm{~atm}$ ) como um líquido azul pálido. A cor azul é devido a transições eletrônicas nas quais duas moléculas no estado fundamental triplete, ao colidirem, são excitadas aos estados singlete por um único fóton na região do visível $(630 \mathrm{~nm}$ ou $578 \mathrm{~nm}){ }^{29,30}$ No entanto, a coloração azul do céu não tem relação com essas transições eletrônicas que só ocorrem na fase líquida, condensada, uma vez que o tempo de colisão entre duas moléculas na fase gasosa não é suficiente para que sejam excitadas pelo fóton. De modo que o fenômeno responsável pela coloração 


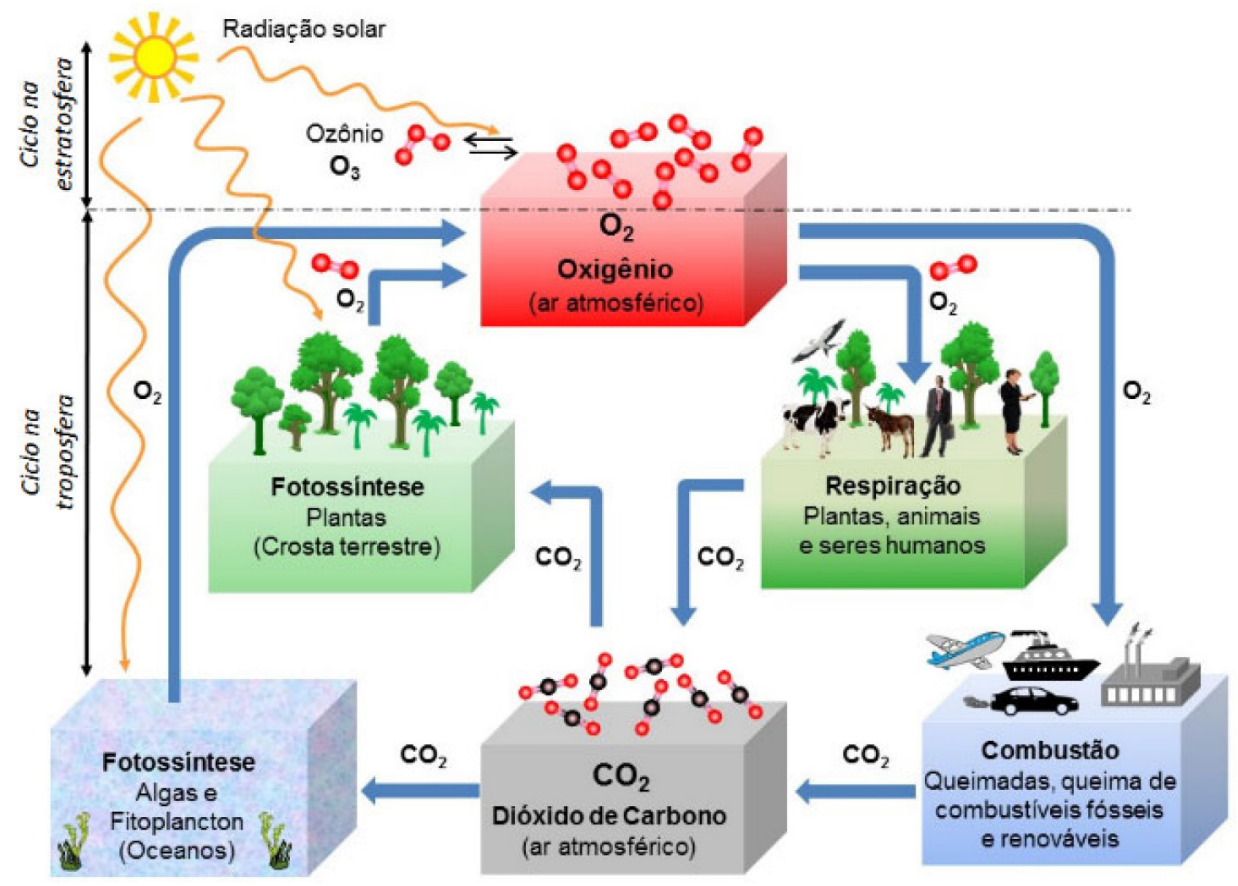

Figura 3. Ciclo do oxigênio

azul do céu tem outra origem, é devido ao espalhamento Rayleigh. Contudo, os estados singlete na fase gasosa podem ser alcançados fotoquimicamente por transferência de energia de uma molécula excitada, quimicamente ou em um tubo de descarga elétrica. Esses estados são importantes em muitos processos de oxidação. ${ }^{26,31-33}$

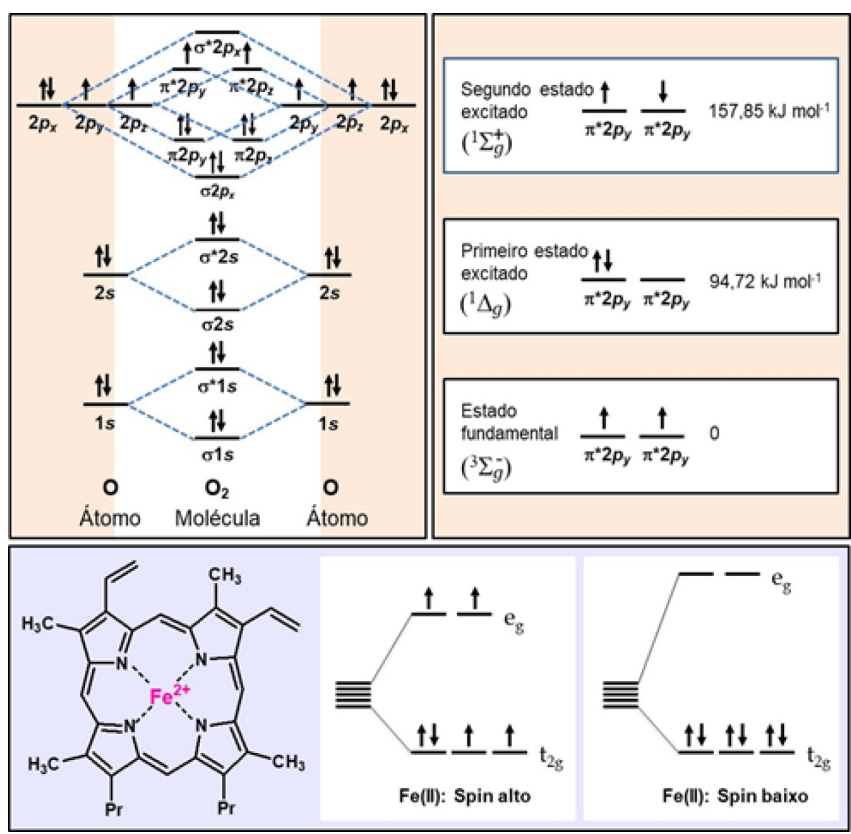

Figura 4. Estados energéticos da molécula de $\mathrm{O}_{2}$ e do $\mathrm{Fe}(\mathrm{II})$ e estrutura do complexo Fe(II)-porfirina (grupo heme)

Do vasto campo de aplicações do oxigênio a mais nobre delas é, sem dúvida, a manutenção da vida. O oxigênio é responsável por converter a energia armazenada em moléculas orgânicas em ATP, que permite à célula desempenhar diversas funções metabólicas. No entanto, a solubilidade do $\mathrm{O}_{2}$ no plasma é muito baixa, cerca de $2,3 \mathrm{~mL} \mathrm{~L}^{-1},{ }^{34}$ quantidade insuficiente para atender a todas as demandas das células. Por isso, são necessários transportadores que permitam que quantidades maiores de oxigênio cheguem às células; papel esse desempenhado de forma eficiente por metaloproteínas.

Na maioria dos organismos aeróbios superiores essas metaloproteínas contém o anel porfirínico de $\mathrm{Fe}(\mathrm{II})$, denominado grupo heme, a exemplo da hemoglobina, responsável pelo transporte de $\mathrm{O}_{2}$ dos pulmões até as células, e da mioglobina que armazena oxigênio na célula, como ilustrado na Figura 4.

A hemoglobina contém quatro grupos heme, com Fe(II) ligado a quatro átomos de nitrogênio do anel porfirínico de estrutura rígida plana. $\mathrm{Na}$ desoxi-hemoglobina, o Fe(II) de spin alto é pentacoordenado, com o quinto sítio ocupado pelo nitrogênio da globulina, em um arranjo piramidal quadrático. Nesta configuração, o tamanho do íon Fe(II) não permite que ocupe o centro do anel porfirínico, deslocando-se para fora do plano. Oxigênio, ao se ligar reversivelmente à hemoglobina, ocupa o sexto sítio completando a esfera de coordenação do Fe(II) e, por ser um ligante de campo forte, altera a sua configuração eletrônica, passando ao estado de spin baixo. Com essa nova configuração, o raio do Fe(II) contrai e se encaixa perfeitamente na cavidade do anel porfirínico. ${ }^{31,32,35}$

$\mathrm{Na}$ respiração, diferentemente de uma reação de combustão termodinamicamente favorecida entre moléculas orgânicas e $\mathrm{O}_{2}$ que gera rapidamente $\mathrm{CO}_{2}, \mathrm{H}_{2} \mathrm{O}$ e calor, os organismos vivos podem usar o oxigênio de forma controlada para suprir as suas necessidades energéticas. Assim, a oxi-hemoglobina é capaz de transportar $220 \mathrm{~mL}$ de $\mathrm{O}_{2}$ por cada litro de sangue, dos alvéolos até os tecidos, ${ }^{34}$ quantidade suficiente para atender à demanda energética das células na realização de suas funções metabólicas. A mioglobina é uma metaloproteína com apenas um grupo heme e se liga mais fortemente ao $\mathrm{O}_{2}$ que a hemoglobina, atuando, assim, como um armazenador de oxigênio nos tecidos..$^{31,32,35}$

\section{OXIGÊNIO HOSPITALAR}

O uso terapêutico do oxigênio, definido como oxigenoterapia, consiste na sua administração em concentrações superiores às encontradas no ar ambiente visando a melhoria da oxigenação dos tecidos em casos de manifestações de hipóxia (condição em que a concentração de oxigênio no sangue é insuficiente), sendo empregada tanto para o tratamento da hipóxia quanto em sua prevenção, 
em anestesias, reanimações cardiorrespiratórias, bem como na administração de medicamentos por via inalatória/nebulização. ${ }^{36}$

A primeira aplicação medicinal do oxigênio foi feita em 1780 por Chaussier, quando o utilizou para tratar recém-nascidos dispneicos. No ano de 1887, Holzapple gerou oxigênio a partir de clorato de potássio e dióxido de manganês, dispondo posteriormente para tratar casos de pneumonia. Apesar de já em uso, o processo de obtenção do oxigênio para aplicações terapêuticas só foi consolidado no final do século XIX, a partir da produção de ar líquido por compressão e resfriamento, seguido do processo de isolamento do oxigênio via destilação fracionada. ${ }^{37}$

No Brasil, a ANVISA é o órgão responsável por regular a fabricação e o uso dos gases medicinais, uma vez que estes são classificados como medicamentos. A regulação é feita através de Resoluções da Diretoria Colegiada (RDC) e Instruções Normativas (IN). A RDC $n^{\circ} 70$ de $1^{\circ}$ de outubro de 2008 estabelece a lista de gases medicinais de uso consagrado e de baixo risco sujeitos a notificação e os procedimentos para a notificação. Já a RDC n ${ }^{\circ} 301$ e IN n ${ }^{\circ} 38$ de 21 de agosto de 2019 dispõem sobre as Boas Práticas de Fabricação de Medicamentos e complementares a Gases Substâncias Ativas e Gases Medicinais, respectivamente. ${ }^{38}$

O oxigênio destinado ao uso hospitalar é normalmente fornecido no estado gasoso, acondicionado em cilindros de alta pressão, com nível mínimo de pureza de $99 \%$ v/v. Alternativamente, alguns hospitais armazenam o oxigênio na forma líquida, resfriado a $-183^{\circ} \mathrm{C}$ em tanques estacionários isolados termicamente, sendo o líquido vaporizado antes de ser injetado nas linhas de oxigênio locais para administração ao paciente. ${ }^{39}$ Por ser considerado um medicamento, todas as informações técnicas acerca do oxigênio de uso terapêutico estão dispostas na Farmacopeia Brasileira ou outros compêndios internacionais, como as Farmacopeias Americana e Europeia. De acordo com a Brasileira, além do teor mínimo de $99 \%$ de pureza, há outros parâmetros a serem observados para que o oxigênio produzido esteja apto para uso terapêutico como, por exemplo, uma quantidade máxima de vapor d'água de 67 ppm (parte por milhão) e impurezas permitidas para produtos envazados em cilindros, citando-se o monóxido de carbono e dióxido de carbono que podem estar presentes na concentração máxima de 5 e 300 ppm, respectivamente. ${ }^{40}$

Em virtude da emergência de saúde pública ocasionada pelo novo coronavírus a ANVISA permitiu, por meio da RDC no 461/2021, em caráter extraordinário e temporário, a produção e distribuição de oxigênio medicinal com teor mínimo de $95 \%$, com o intuito de ampliar a sua disponibilidade, uma vez que várias regiões do país entraram em crise de abastecimento devido à alta demanda. Vale ressaltar que há um risco associado a erro de medicação devido ao uso de $\mathrm{O}_{2}(\mathrm{~g})$ com pureza inferior a $99 \%$, podendo comprometer a segurança do tratamento do paciente. Nesse aspecto, a própria RDC recomenda o gerenciamento de risco associado à mudança na pureza do oxigênio. Portanto, se faz necessário o conhecimento dos profissionais de saúde acerca do teor utilizado, para que procedam com os critérios de precisão/exatidão adequados no ato da administração em associação com outros fármacos, para não causar danos à vida dos pacientes. ${ }^{41}$ É importante destacar que a Nota Técnica ${ }^{\circ}$ 20/2021 da ANVISA trata da análise de risco com alerta aos profissionais de saúde sobre a necessidade de fazer adequação no tempo de saturação devido à mudança da pureza do oxigênio administrado ao paciente. ${ }^{41}$

\section{FONTE E PRODUÇÃO DE OXIGÊNIO}

\section{Fotossíntese e a produção industrial de oxigênio via criogenia}

A principal fonte para a produção industrial de oxigênio é o ar atmosférico, pois cerca de um quinto da sua composição é oxigênio. $\mathrm{Na}$ troposfera, o oxigênio é produzido pela fotossíntese, um complexo processo realizado por plantas e algas verdes, dividido em dois estágios sequenciais: as reações dependentes da luz e as reações independentes da luz, ou o ciclo de Calvin, Figura 5. ${ }^{31,32}$

Os organismos fotoautotróficos são capazes de armazenar a energia solar em ligações químicas e produzir oxigênio por meio de diversas reações encadeadas. Para isso, empregam como estratégia a clorofila, que contém uma unidade tetrapirrólica com o íon $\mathrm{Mg}$ (II) ligado aos átomos de nitrogênio do anel de clorina de estrutura rígida plana, de forma análoga à hemoglobina. Assim, na etapa dependente da luz, moléculas de clorofila e outros pigmentos que compõem o complexo antena instalado na membrana dos tilacoides capturam fótons através dos fotossistemas I e II (PS I e PS II) acoplados em uma configuração conhecida como "esquema Z", Figura 5.

A etapa luminosa da fotossíntese gera elétrons de alta energia que são transferidos por carreadores intermediários através de várias reações de oxirredução. Oxigênio é produzido pela oxidação da água no PS II e os elétrons fotoexcitados são transferidos por mediadores de oxirredução, resultando na formação de ATP, enquanto NADPH é produzido no PS I. Ambas armazenam energia solar nas ligações químicas. Na etapa escura, a energia armazenada em ATP e NADPH será utilizada na construção de moléculas orgânicas a partir do $\mathrm{CO}_{2}$ no ciclo de Calvin.

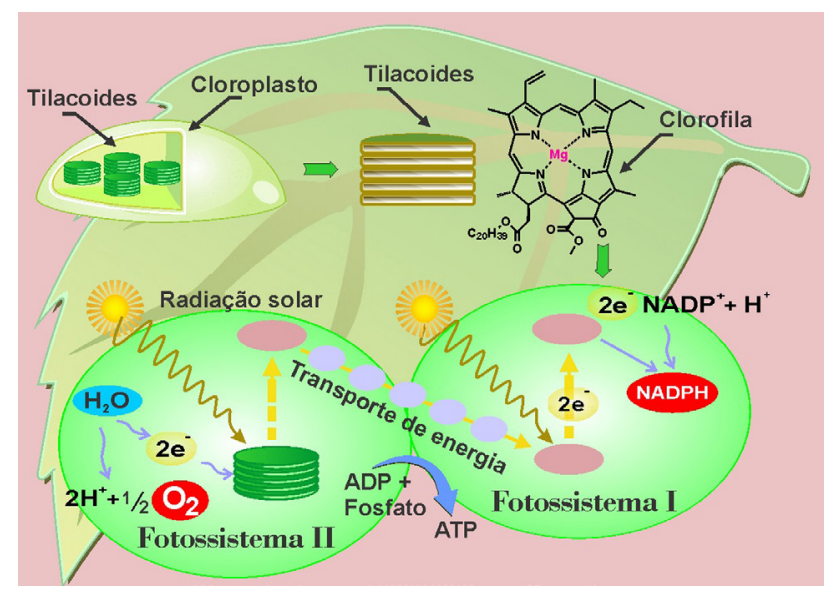

Figura 5. Representação genérica do "esquema Z" da fotossíntese, com produção de $\mathrm{O}_{2}$ no fotossistema II

$\mathrm{O}$ ar atmosférico é, majoritariamente, composto por nitrogênio (78\%), seguido de oxigênio $(21 \%)$, argônio $(0,9 \%)$ e outros gases minoritários como dióxido de carbono, outros gases nobres e metano, que juntos somam $0,1 \%$ da composição em volume do ar seco, Figura 6. A separação criogênica do ar atmosférico é a tecnologia mais eficiente e econômica para a produção de grandes quantidades de oxigênio, nitrogênio e argônio como produtos gasosos ou líquidos..$^{42} \mathrm{O}$ primeiro processo foi desenvolvido por C. Von Linde e W. Hampson no final do século XIX baseado na compressão isotérmica do ar, seguida de expansão adiabática para permitir o resfriamento pelo efeito Joule-Thompson, Quadro 1. ${ }^{26} \mathrm{O}$ processo foi aprimorado por G. Claude, com a expansão do gás comprimido realizando trabalho, quase isentropicamente, para comprimir o gás de entrada. Com essa modificação, Claude conseguiu atingir pela primeira vez temperaturas baixíssimas com uma pressão de apenas 40 bar. ${ }^{43}$

O processo de produção industrial de oxigênio consiste, inicialmente, na coleta e pressurização do ar atmosférico úmido por um compressor que fornece energia mecânica, elevando pressão e temperatura da mistura gasosa, Figura 6. Vale ressaltar que o ar comporta quantidades variáveis de vapor d'água a depender da temperatura, atingindo um percentual máximo, quando ocorre a saturação. À pressão de 1 atmosfera, o percentual máximo de 


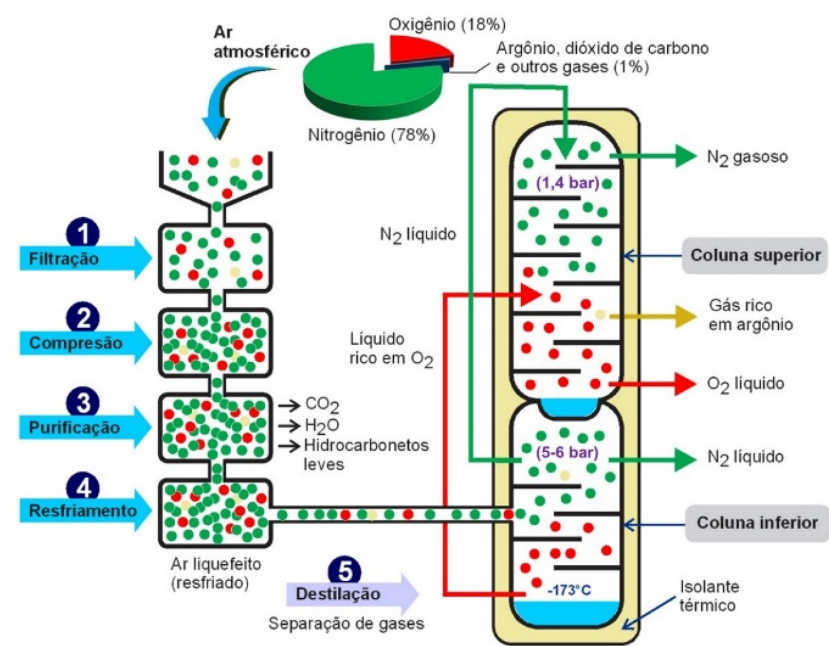

Figura 6. Composição do ar seco e esquema de uma planta industrial do sistema de separação criogênica do ar atmosférico

vapor d'água no ar é de $4 \%$ em volume à temperatura de $30{ }^{\circ} \mathrm{C} .{ }^{44}$ Posteriormente, o gás passa por etapas de filtração e condensação com o intuito de remover vapor d'água, partículas sólidas, dióxido de carbono e hidrocarbonetos leves. A contaminação por estes resíduos pode danificar o aparelho de destilação, tanto por incrustação de sólidos, como pela formação de uma mistura explosiva entre moléculas orgânicas e oxigênio líquido. ${ }^{45}$ Uma vez purificado e seco, o ar pressurizado tem sua temperatura drasticamente reduzida a $-200{ }^{\circ} \mathrm{C}$, tanto por resfriamento direto em um trocador de calor, em que o vapor do ar já liquefeito circula, quanto por expansão através de uma válvula, por conta do efeito Joule-Thompson, cujo detalhamento do conceito por trás da liquefação do ar se encontra no Quadro 1. O ar liquefeito é, então, enviado ao sistema de destilação, Figura $6 .{ }^{45}$

O sistema de destilação do ar liquefeito é composto por duas colunas. A coluna inferior (CI), por onde o ar líquido entra, é mantida sob alta pressão (5-6 bar). Na base, em que a temperatura é maior $\left(-173^{\circ} \mathrm{C}\right)$, o líquido acumulado se torna rico em $\mathrm{O}_{2}$. Isso ocorre porque $\mathrm{N}_{2}$ é mais volátil (ponto de ebulição $-196^{\circ} \mathrm{C}$ ) que $\mathrm{O}_{2}$ (ponto de ebulição $-183{ }^{\circ} \mathrm{C}$ ). No topo da $\mathrm{CI}, \mathrm{N}_{2}$ é condensado, gerando uma corrente pressurizada líquida. Parte dessa corrente é direcionada para o topo da coluna superior (CS), mantida sob pressão moderada (1,4 bar). A despressurização reduz a temperatura dessa corrente, o que garante a temperatura mais baixa do sistema no topo da CS, condensando substâncias menos voláteis. O gás $\mathrm{N}_{2}$ é removido no topo da $\mathrm{CS} .^{45}$

A coluna CS é alimentada com o líquido rico em $\mathrm{O}_{2}$ contido no fundo da CI. O líquido perde mais vapor de $\mathrm{N}_{2}$ conforme desce pelos pratos. $\mathrm{O}$ argônio, outro componente importante do ar atmosférico, por ter ponto de ebulição intermediário $\left(-186^{\circ} \mathrm{C}\right)$, concentra-se em um ponto abaixo da metade da coluna CS. A corrente rica em argônio (cerca de 10\%) é direcionada para outra coluna de destilação onde é purificado. No fundo da coluna $\mathrm{CS}, \mathrm{o} \mathrm{O}_{2}$ quase puro que se acumula está 2-3 K mais frio que a temperatura de liquefação do $\mathrm{N}_{2}$ na CI. Estas duas seções trocam calor com dupla função. $\mathrm{O}$ condensador do $\mathrm{N}_{2}$ na CI sob alta pressão é o $\mathrm{O}_{2}$ líquido, mais frio, sob pressão moderada. Da mesma forma, a condensação do $\mathrm{N}_{2}$ atua como refervedora da CS, mantendo seu fluxo de vapor ascendente. Oxigênio líquido com elevado grau de pureza é obtido por esse processo. ${ }^{45}$

\section{Concentrador de oxigênio atmosférico: alternativa ao processo criogênico}

A oxigenoterapia é um tipo de tratamento administrado não apenas aos pacientes infectados pelo vírus SARS-CoV-2 mas para todos os que possuem algum comprometimento do sistema respiratório. Nos casos graves, em que o paciente precisa de internação e cuidados intensivos, o gás oxigênio deve cumprir com os requisitos exigidos para uso hospitalar (e.g. teor de pureza) e sua produção - nesse caso - ocorre via criogenia. No entanto, para situações de uso regular, o suprimento de $\mathrm{O}_{2}$ ao paciente pode provir de um cilindro de oxigênio para uso domiciliar/hospitalar ou de um concentrador de oxigênio.

O concentrador de oxigênio é um aparelho relativamente pequeno e os mais modernos são portáteis, podendo ser usado ligado à corrente elétrica ou através de uma bateria, e produz $\mathrm{O}_{2}$ com 95\% de pureza empregando a tecnologia PSA (Pressure Swing Adsorption) ou VPSA (Vacuum Pressure Swing Adsorption). ${ }^{46-48}$ Esses dispositivos foram criados no início dos anos 70 e a tecnologia por trás do seu funcionamento é baseada nos fenômenos de adsorção do gás nitrogênio (maior constituinte gasoso do ar atmosférico) através de zeólitos seletivos. A Figura 7 apresenta um esquema geral simplificado do seu funcionamento.

$\mathrm{O}$ ar que entra no equipamento é sugado por meio de um compressor, cujo motor funciona seja ligado à corrente elétrica, seja à pilha/bateria (no caso de equipamentos portáteis). $\mathrm{O}$ sistema possui um silenciador para evitar ruídos durante o funcionamento. $\mathrm{O}$ circuito elétrico tem a função de controlar as válvulas solenoides, que atuam no sentido de promover o processo de filtração do ar e limpeza dos cilindros, de modo a dessorver o gás nitrogênio, devolvendo-o para o ar atmosférico. A presença de um tanque logo após a compressão exerce um papel de alívio de pressão. Do mesmo modo, o tanque de oxigênio a 90-95\% de pureza é necessário para manter todo o sistema em pressão segura de trabalho. Ao final, a saída do oxigênio é feita por meio de um fluxômetro, cuja quantidade dependerá da prescrição médica.

Os dispositivos que produzem oxigênio via PSA ou VPSA operam por processos envolvendo adsorção, dessorção e outras etapas complementares para a obtenção de $\mathrm{O}_{2}$ com pureza entre $80-95 \% .{ }^{49}$ Esses processos podem ocorrer, aproximadamente, à pressão atmosférica ou em um nível mais elevado de pressão. Em qualquer um dos casos, o nitrogênio (separado a partir do ar pelo processo adsorção) é um rejeito, sendo retornado ao ar. Nos processos que ocorrem a pressões próximas à atmosfera, o nitrogênio é dessorvido a partir de uma redução de pressão (pressão abaixo da pressão atmosférica). Esse "vácuo" é aplicado em direção oposta ao fluxo de alimentação do equipamento e uma bomba de vácuo é acoplada para facilitar a evacuação do $\mathrm{N}_{2}$ ao passo que um soprador de ar realimenta o sistema, iniciando um novo ciclo de operação. No caso onde o processo ocorre a uma pressão elevada, a dessorção do $\mathrm{N}_{2}$ é feita pela redução da pressão do sistema até, aproximadamente, a pressão atmosférica e, então, é feita uma purga do adsorvente com o próprio gás enriquecido com oxigênio, cujo fluxo também é realizado contra-corrente ao fluxo de entrada do ar. Em qualquer um dos processos, o material gasoso que retorna ao ambiente é constituído por nitrogênio (84-92\%) e oxigênio $(7,5$ $15 \%$ ), em base seca, desconsiderando as quantidades de argônio e gás carbônico. ${ }^{49}$

Do ponto de vista da Química, o aspecto mais importante a ser tratado se refere ao fenômeno de adsorção seletiva do gás nitrogênio, o qual fica aprisionado na cavidade do zeólito. Zeólitos, em destaque na Figura 7, são estruturas microporosas de aluminossilicatos com fórmula geral $\left\{\left[\mathrm{M}^{\mathrm{n}+}\right]_{\mathrm{x} / \mathrm{n} \cdot} \cdot\left[\mathrm{H}_{2} \mathrm{O}\right]_{\mathrm{m}}\right\}\left\{\left[\mathrm{AlO}_{2}\right]_{\mathrm{x}} \cdot\left[\mathrm{SiO}_{2}\right]_{\mathrm{y}}\right\}^{\mathrm{x}-}$, em que $\mathrm{M}^{\mathrm{n}+}$ cátions e moléculas de água ligam-se no interior da cavidade, ou poros, da rede Al-O-Si. Pequenas moléculas neutras como $\mathrm{CO}_{2}, \mathrm{NH}_{3}$, $\mathrm{O}_{2}, \mathrm{~N}_{2}$ e hidrocarbonetos (incluindo hidrocarbonetos aromáticos) podem ser adsorvidas, seja na superfície do zeólito ou no interior da cavidade. ${ }^{50}$ 
Quadro 1. O efeito Joule-Thomson na produção industrial de $\mathrm{O}_{2}$ molecular a partir da liquefação do ar

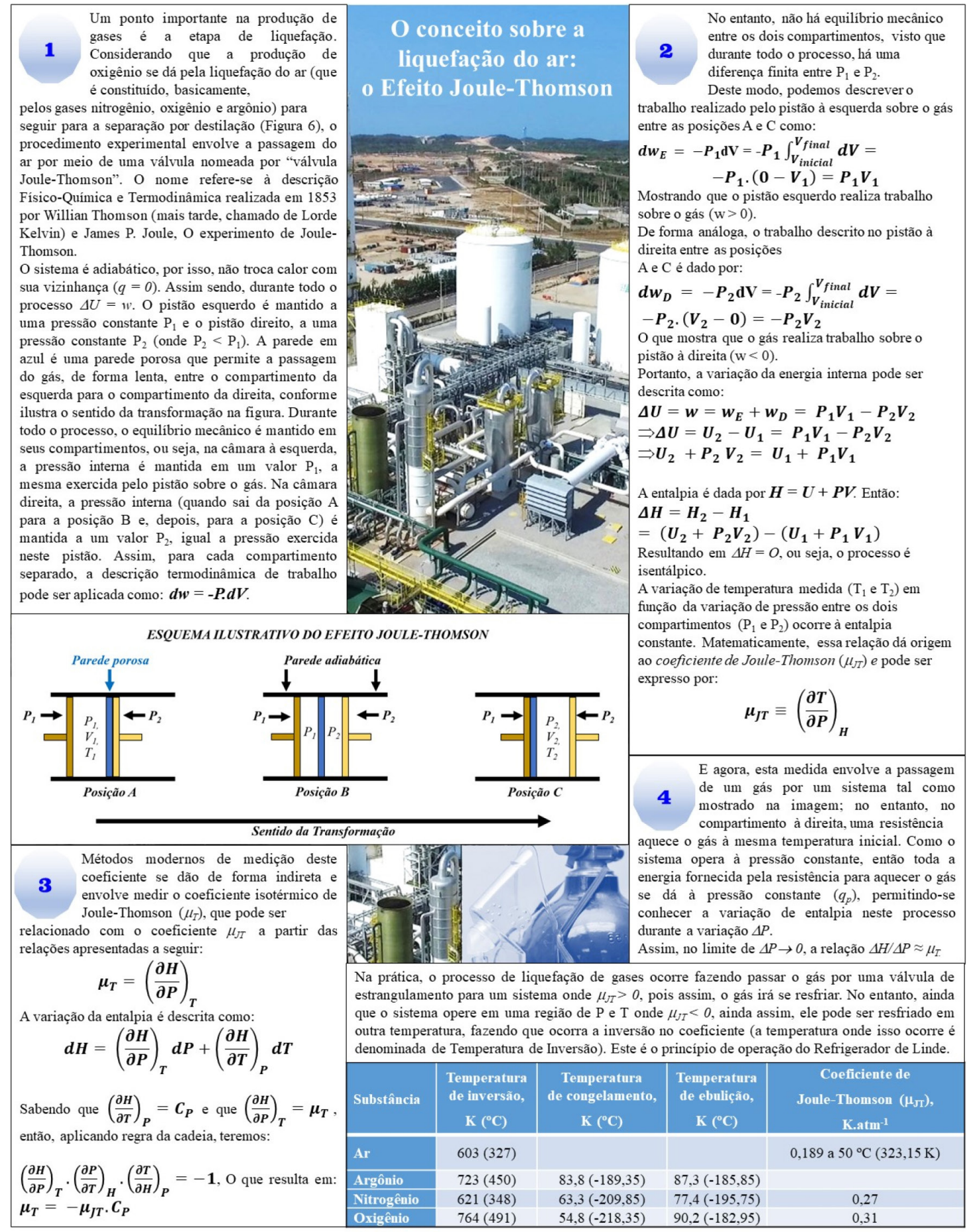

A presença dos cátions $\left(\mathrm{M}^{\mathrm{n}+}\right)$ atua no sentido de compensar o desiquilíbrio de carga criado pelo íon $\mathrm{Al}(\mathrm{III})$ na estrutura. Assim, a presença do cátion $\mathrm{M}^{\mathrm{n}+}$ cria um campo eletrostático não-uniforme dentro da cavidade do zeólito que se torna responsável pela adsorção de gás que passa pela cavidade. Moléculas de gás podem ser aprisionadas na cavidade do zeólito em diferentes extensões a depender da interação do campo elétrico da molécula com o campo eletrostático presente na cavidade. Um zeólito pode reter uma molécula de gás em sua superfície, em um sítio específico ou em seu poro. Essa última condição, chamada de preenchimento de poros, dependerá do número, tamanho e volume de poros presentes no material zeolítico. ${ }^{51}$
Zeólitos com uma proporção baixa entre $\mathrm{Si} / \mathrm{Al}$ conseguem aprisionar $\mathrm{N}_{2}$ mais seletivamente que $\mathrm{O}_{2}$. Os primeiros estudos voltados à separação de gases envolveram estudos com zeólitos do tipo 5A ( $\mathrm{CaA})$ e $13 \mathrm{X}(\mathrm{NaX})$. O desenvolvimento nesse tipo de trabalho conduziu a sistemas zeolíticos cada vez mais eficientes no processo de separação de gases. Em se tratando do ar atmosférico, os melhores resultados foram aqueles empregando o cátion $\mathrm{Li}^{+}(99 \%$ de troca em relação ao $\mathrm{Na}^{+}$) em um zeólito com proporção $\mathrm{Si} / \mathrm{Al}=1$. Esse estudo mostrou que o zeólito Li-X não é capaz de aprisionar o argônio, sendo esse o motivo pelo qual o teor de oxigênio apresentase a um máximo de $95 \% .^{52,53}$ 


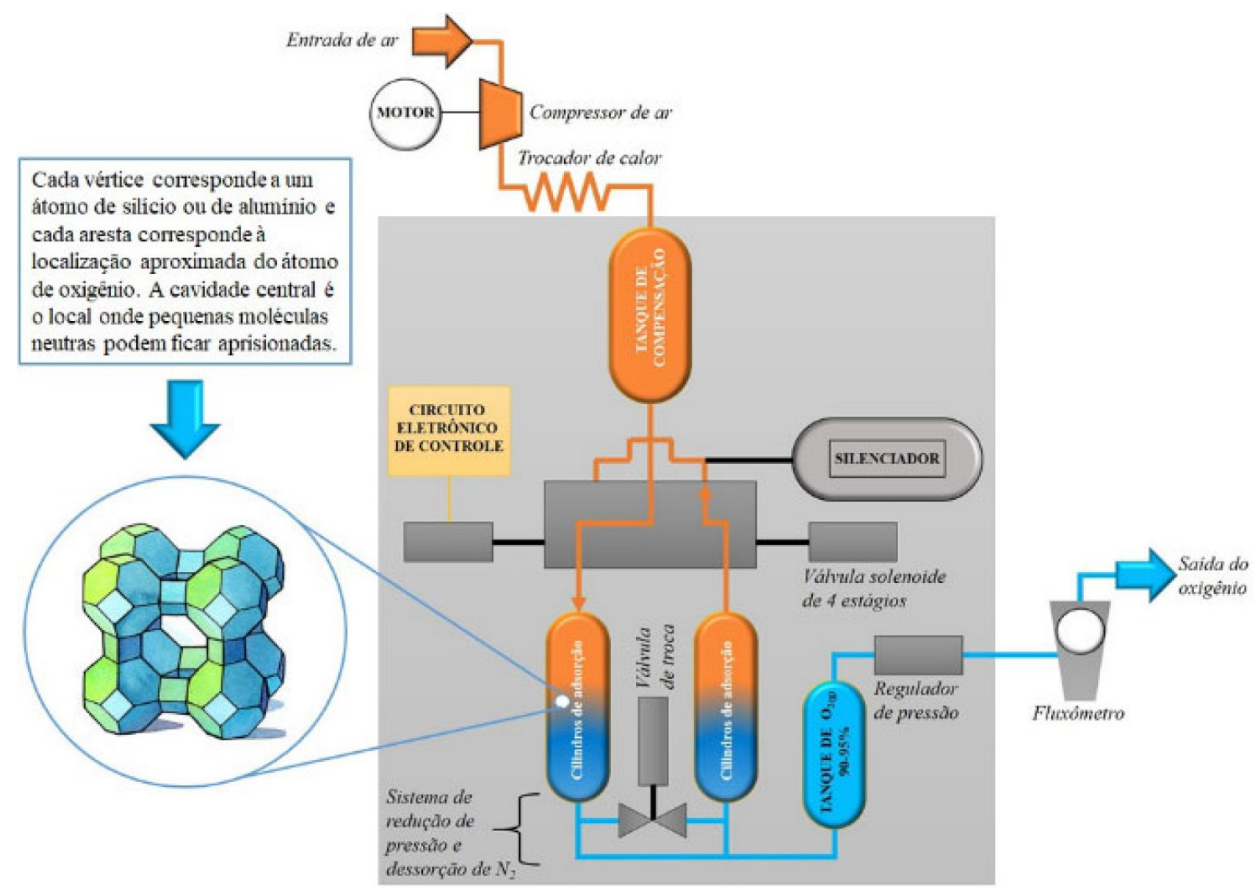

Figura 7. Esquema simplificado de funcionamento de um concentrador de oxigênio (adaptado da ref. 49). Em destaque, representação geral de zeólito constituído de silício, alumínio e oxigênio, adaptada da ref. 50

\section{Capacidade e localização de produção; uso industrial do oxigênio}

A produção criogênica de oxigênio a partir da destilação fracionada do ar atmosférico constitui-se como a principal fonte de fornecimento deste produto, e a maior demanda mundial por oxigênio obtido industrialmente é na produção de aço. Nesse processo, oxigênio reage com o coque produzindo monóxido de carbono. $\mathrm{O}$ calor liberado da reação exotérmica é utilizado para auxiliar na rápida redução dos óxidos de ferro por $\mathrm{CO}$ e carbono para obtenção do ferrogusa. É preferível usar, nesse processo, oxigênio ao invés do ar para que não haja desperdício de energia com aquecimento do nitrogênio. ${ }^{32}$

O ferro-gusa líquido e sucata de aço são, então, carregados em conversores e submetidos a sopro de oxigênio puro. A queima do carbono (e do silício) do ferro-gusa causa aumento de temperatura e diminuição do teor de carbono (entre 0,03 e 0,06\% de carbono). Em 2019, o Brasil produziu 32,455 x $10^{6}$ ton de aço bruto, com um consumo de $24,764 \times 10^{6}$ ton de oxigênio. ${ }^{54}$ No entanto, esse processo não exige o uso de oxigênio de elevado grau de pureza, podendo-se usar oxigênio $92 \%,{ }^{55}$ ao contrário do uso hospitalar que exige um nível mínimo de pureza de $99 \%$.

A maioria das plantas de produção criogênica de oxigênio no Brasil está localizada na região Sudeste, concentrando $85,9 \%$ de toda a produção nacional. ${ }^{54}$ Oxigênio é comercializado na forma líquida e gasosa com diferentes graus de pureza, que pode variar de $90 \%$ a 99,9999\%. ${ }^{56,57}$ A logística de transporte do oxigênio liquefeito é complexa e demanda tanques criogênicos móveis com estrutura para suportar baixas temperaturas. Dessa forma, a produção local seria uma boa estratégia alternativa para os casos em que pacientes portadores de doenças cardiorrespiratórias precisam de suplementação de oxigênio (oxigenoterapia) e estão em localidades distantes das regiões produtoras de oxigênio pelo processo criogênico.

$\mathrm{O}$ uso dos concentradores de oxigênio vem ganhando espaço como alternativa ao uso dos cilindros de gás. Recentemente, um grupo de empresas da iniciativa privada destinou cerca de $\mathrm{R} \$ 35$ milhões para a aquisição desses equipamentos que foram doados ao Sistema Único de Saúde (SUS). O montante é o suficiente para adquirir pouco mais de 5.100 unidades de concentradores de oxigênio. ${ }^{58}$ Contudo, a capacidade de produção de oxigênio usando o compressor é muito menor do que a tecnologia criogênica. Como exemplo, a produção criogênica de $\mathrm{O}_{2}$ é da ordem de 3000 toneladas por dia (ou maior, a depender da planta de produção), enquanto que a produção por sistema pressurizado por adsorção (usando a tecnologia PSA) é inferior a 300 toneladas por dia. ${ }^{53}$ Porém, dada a portabilidade e facilidade de uso, os concentradores de oxigênio se tornaram uma alternativa interessante na ausência de um cilindro de gás, principalmente nos casos de pacientes que não necessitem de oxigênio com pureza acima de $99 \%$.

A implantação de miniusinas de produção de oxigênio em locais estratégicos pode minimizar o problema de desabastecimento de oxigênio nos hospitais em momentos críticos. Porém, requer um elevado investimento inicial na aquisição de compressores, filtros, colunas recheadas de zeólitos, cilindros e válvulas adequadas. Em contrapartida, as miniusinas, capazes de produzir $\mathrm{O}_{2}$ com até $95 \%$ de pureza, não exigem mão-de-obra especializada para operá-las, não requerem gasto elevado com manutenção e, assim que montadas, estão prontas para o uso, diferentemente de um sistema industrial de grande escala. ${ }^{46-48}$

\section{MEDIDA DO NÍVEL DE OXIGÊNIO NO SANGUE - OXIMETRIA}

Alguns pacientes acometidos pelo Sars-CoV-2 necessitam de suplemento de $\mathrm{O}_{2}$ por apresentarem baixa saturação de oxigênio $\left(\mathrm{SpO}_{2}\right)$, ou seja, reduzida porcentagem de oxi-hemoglobina, proteína que leva oxigênio dos pulmões para os tecidos, devido ao comprometimento da função pulmonar. Em adultos, níveis de $\mathrm{SpO}_{2}$ entre $95-98 \%$ são considerados normais; estando abaixo de $90 \%$, já se faz necessário suporte de oxigênio. ${ }^{59-61}$

O tratamento de doenças agudas reversíveis é, em geral, de competência das Unidades de Terapia Intensiva (UTIs). Para esses casos, a primeira instância é garantir os níveis de oxigênio arterial adequados para evitar hipóxia tecidual. ${ }^{62}$ A doença causada pelo SARS-CoV-2 leva os pacientes a um estado de Severa Síndrome 
Respiratória Aguda, com sintomas diversos, mas, em casos graves da COVID-19, com a necessidade de internação e intubação do paciente para ventilação mecânica. Esse quadro clínico, denominado pela classe médica por Hipóxia silenciosa, merece atenção, principalmente nos primeiros estágios da infecção, de modo a evitar o comprometimento do sistema respiratório. ${ }^{63}$ De imediato, o paciente precisa ser analisado e o nível de oxigenação medido para que o profissional da saúde saiba como conduzir o atendimento e tratamento. A avaliação dos níveis de oxigênio é realizada pela mensuração de algumas variáveis que permitem avaliar o consumo e suprimento desse gás. Para isso, alguns procedimentos invasivos são realizados; porém, a manipulação invasiva aumenta o risco de agravamento do estado geral do paciente. ${ }^{62}$ Nesse sentido, desenvolver procedimentos seguros e não invasivos tornam o atendimento menos arriscado para o paciente e mais célere ao profissional da área de saúde. Por isso, o desenvolvimento de dispositivos que permitem medir o nível de oxigênio no sangue - os oxímetros - tem ganhado espaço no meio hospitalar. Uma lista de dispositivos disponíveis no mercado foi reportada por Steppan e Hogue. ${ }^{64}$

A saturação de oxigênio pode ser aferida por meio de coleta de sangue, quando o objetivo é obter valores exatos, como por exemplo em casos em que o paciente precisa ser monitorado continuamente, ou através dos oxímetros de pulso/estacionário ou de dedo, ambos utilizados em hospitais, Figura 8. O oxímetro mede, com elevada eficiência, a saturação de oxigênio arterial nas extremidades, denotada por $\mathrm{SpO}_{2}$. Por outro lado, a medida de saturação sanguínea de oxigênio $\left(\mathrm{SaO}_{2}\right)$ é efetuada de forma invasiva e possui uma relação com $\mathrm{SpO}_{2}$, cuja equivalência é dada por um fator de correção $\mathrm{R}$ entre essas duas medidas. ${ }^{65,66}$ Por isso, o uso do oxímetro se torna uma necessidade real em ambientes clínicos, uma vez que o oxímetro é um dispositivo simples que é utilizado acoplando-o a uma parte do corpo do paciente, normalmente, o dedo, o pulso ou o lóbulo da orelha. ${ }^{67}$

Para compreender o funcionamento desse dispositivo, é importante mapear como esse gás, crucial para a vida, está distribuído no sangue. O sangue contendo a maior quantidade de oxigênio é denominado de sangue arterial, enquanto o sangue venoso é aquele pobre em oxigênio. ${ }^{68}$

Dos pulmões até os tecidos mais distantes, o oxigênio é conduzido, principalmente, pela hemoglobina até os diferentes tecidos e células, Figura 8.

De todo o oxigênio presente na corrente sanguínea, 97-98\% está presente na forma de oxi-hemoglobina $\left(\mathrm{HbO}_{2}\right)$, que é formada pela ligação do $\mathrm{O}_{2}$ ao grupo heme ( $\mathrm{Fe}^{\mathrm{II}}$-protoporfirina IX) da hemoglobina $(\mathrm{Hb})$, conforme indicado na Figura 8. Cerca de 2-3\% do oxigênio $\left(\mathrm{O}_{2}\right)$ encontra-se dissolvido no plasma. ${ }^{68} \mathrm{~A}$ quantidade de oxigênio arterial presente no sangue pode ser medida de acordo com a equação 2 (Quadro 2).

$\mathrm{SpO}_{2}$ mantem-se, aproximadamente, constante ao longo do sistema arterial, uma vez que o oxigênio é extraído apenas nos capilares. Uma vez dissociado da $\mathrm{HbO}_{2}$, o oxigênio dissolvido no sangue arterial pode ser medido através da pressão parcial desse gás $\left(\mathrm{PaO}_{2}\right) \cdot \mathrm{PaO}_{2}$ e $\mathrm{SpO}_{2}$ são os parâmetros de maior significância clínica e fisiológica, visto que fornecem informações sobre a capacidade de fornecimento de oxigênio aos tecidos. $\mathrm{PaO}_{2}$ é obtido a partir de medidas da amostra do sangue arterial em analisador específico de gás, enquanto $\mathrm{SpO}_{2}$ pode ser obtido a partir de medidas oximétricas. ${ }^{68}$ A correlação entre esses dois parâmetros é dada pela curva de dissociação, Figura 9A.

O nível considerado normal de saturação de oxigênio é de $95-99 \%,{ }^{68,72}$ porém, esses valores podem ser alterados a depender do estado clínico do paciente, bem como das condições fisiológicas ( $\mathrm{pH}$ no plasma sanguíneo, temperatura e presença de gás carbônico). $\mathrm{O}$ resultado de $\mathrm{SpO}_{2}$ por oximetria está muito bem relacionado ao valor de $\mathrm{SaO}_{2}$, porém, nem sempre pode refletir a real pressão parcial de oxigênio. Na curva mostrada na Figura 9A, percebe-se que a uma pressão $\mathrm{PaO}_{2}$ de $104 \mathrm{mmHg}$, a medida de saturação $\left(\mathrm{SpO}_{2}\right)$ aponta um valor de 98-99\%, quadro clínico considerado normal. No entanto, a queda da medida por oximetria $\left(\mathrm{SpO}_{2}\right)$ para um valor de $75 \%$ corresponde a uma pressão parcial $\left(\mathrm{PaO}_{2}\right)$ de $40 \mathrm{mmHg}$, considerado um quadro clínico hipoxêmico. Ou seja, uma queda sutil na medida de saturação de oxigênio causa uma queda abrupta na pressão desse gás. A Tabela 1 apresenta a situação de pacientes a partir dos níveis de saturação de oxigênio. Uma análise mais detalhada sobre a curva de dissociação da oxi-hemoglobina está fora do escopo deste artigo, mas os detalhes podem ser obtidos na literatura pertinente..$^{73-75}$

Tabela 1. Correlação entre a leitura do teor de saturação de oxigênio $\left(\mathrm{HbO}_{2}\right)$ e o estado clínico de um paciente ${ }^{73}$

\begin{tabular}{cc}
\hline $\begin{array}{c}\text { Leitura do nível de saturação de } \\
\text { oxigênio }\end{array}$ & Condição clínica do paciente \\
\hline $95-99 \%$ & Normal \\
$90-95 \%$ & Comprometimento respiratório \\
$<90 \%$ & Hipoxêmico \\
$85-90 \%$ & Severo comprometimento respiratório \\
$<75 \%$ & Severa hipoxemia, presença de cianose \\
\hline
\end{tabular}

O princípio que permite obter informações sobre a saturação de oxigênio é baseado na absorção de radiação eletromagnética das

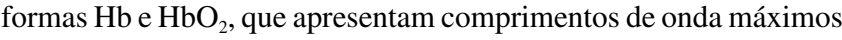
de absorção em diferentes regiões do espectro eletromagnético, tal como ilustra a Figura 9B.

A medida oximétrica é feita pelo uso de radiação eletromagnética em duas frequências diferentes (ou seja, dois comprimentos de onda distintos). Para isso, faz-se necessário o uso de um sistema LED (light emitting diode) composto por uma luz de comprimento de onda $660 \mathrm{~nm}$ e outra, na região do infravermelho, com comprimento de onda de

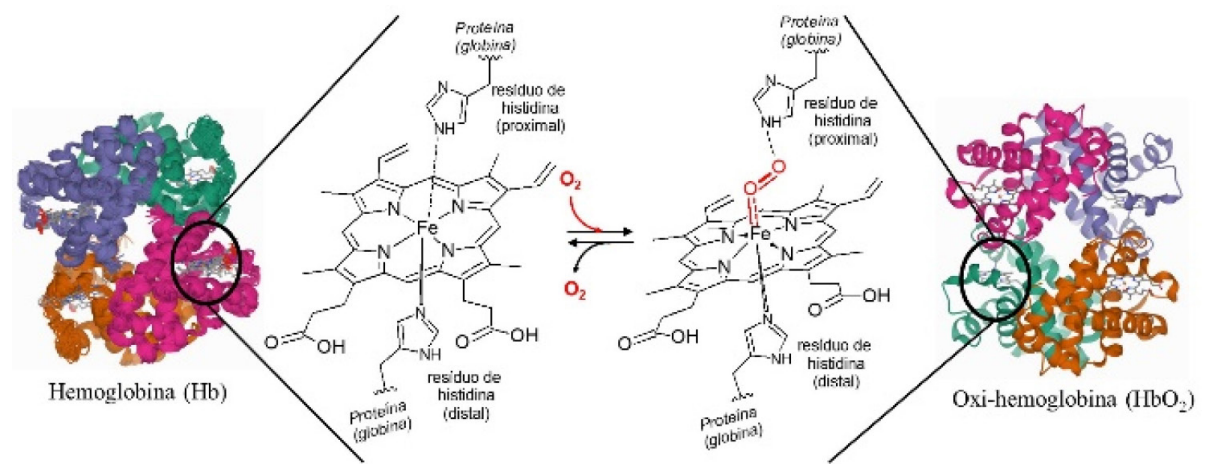

Figura 8. Representação estrutural das formas oxigenada, ${ }^{69} \mathrm{HbO}_{2}$ e desoxigenada ${ }^{70} \mathrm{Hb}$ da hemoglobina e seus respectivos centros alostéricos ${ }^{71}$ 

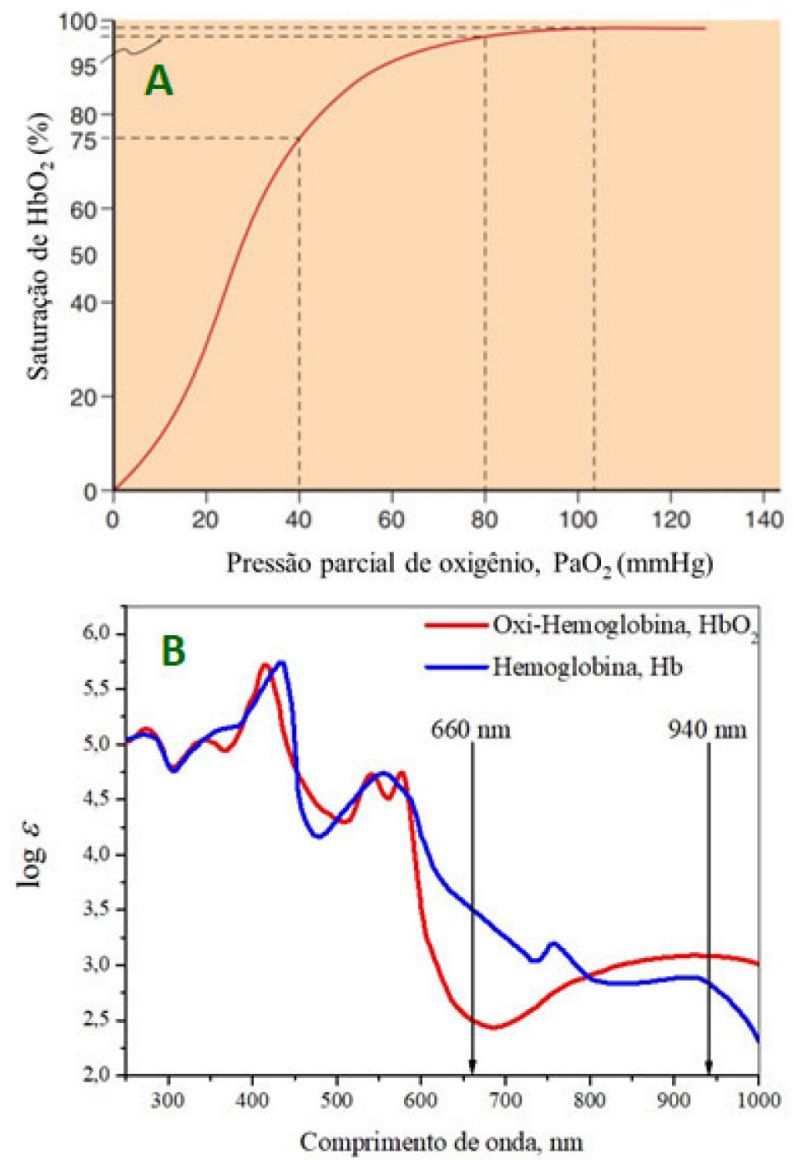

Figura 9. (A) Curva de dissociação da $\mathrm{HbO}_{2}$ correlacionando o teor de oxigênio e a pressão parcial de oxigênio dissolvido presente no sangue arterial (adaptado de Mildenhall); ${ }^{73}$ (B) Espectro eletrônico das formas oxigenada $\left(\mathrm{HbO}_{2}\right.$ ) e não oxigenada $(\mathrm{Hb})$ da hemoglobina (adaptado de Scott Prahl) ${ }^{76}$

$940 \mathrm{~nm}^{65}$ (detalhes na Figura 9B) e o resultado da medida pode ser obtido a partir da análise de um fotopletismograma, Figura 10.

A fotopletismografia é a medida de absorção de luz que ocorre durante as diferentes fases do ciclo cardíaco (sístole e diástole). Durante o ciclo sistólico, há um aumento no volume de sangue arterial e consequente aumento na absorção de luz $\left(I_{s}\right)$. De forma análoga, durante a diástole, há uma redução na absorção de luz $\left(I_{d}\right)$ como resultado da redução no volume de sangue arterial. Assim, a análise da fotopletismografia para cada comprimento de onda monitorado $(660 \mathrm{~nm}$ e $940 \mathrm{~nm})$ resulta em uma relação (R) que está associada ao nível de saturação de oxigênio $\left(\mathrm{SaO}_{2}\right)$. A intensidade $I_{s}$ é medida como sendo a amplitude do sinal da fotopletismografia, sendo relativa ao sinal elétrico alternado (AC) capturado pelo detector (fotodiodo), enquanto a intensidade $I_{d}$ é a linha de base, sendo capturada pelo fotodiodo e estabelecida como o sinal elétrico direto (DC). ${ }^{68}$

Como se trata de medida fotométrica, a aplicação da Lei de Lambert-Beer pode ser feita e manipulada para contemplar a análise da fotopletismografia (Equações 3, 4 e 5, Quadro 2).

A escolha dos comprimentos de onda é feita de modo que a absorção das espécies $\mathrm{Hb}$ e $\mathrm{HbO}_{2}$ sejam diferentes o suficiente para

Quadro 2. Equações matemáticas utilizadas para descrever o processo de medição da saturação de oxigênio no sangue via medida por oximetria

$$
\mathrm{SpO}_{2}=\frac{\left[\mathrm{HbO}_{2}\right]}{\left(\left[\mathrm{HbO}_{2}\right]+[\mathrm{Hb}]\right)}
$$

Onde $\mathrm{SpO}_{2}$ é a saturação de oxigênio arterial, medida pelo oxímetro; $\mathrm{HbO}_{2}$ e $\mathrm{Hb}$ são, respectivamente, oxi-hemoglobina e desoxi-hemoglobina

$$
A_{\lambda}=\varepsilon_{\lambda} \cdot b . C
$$

Onde $A_{\lambda}$ é a absorvância do material a um comprimento de onda específico; $\varepsilon_{\lambda}$ é a absortividade do material em um comprimento de onda específico, medido em $\mathrm{dm}^{3} \mathrm{~mol}^{-1} \mathrm{~cm}^{-1} ; b$ é o caminho óptico, medido em $\mathrm{cm} ; C$ é a concentração do material em análise, em geral, dado em $\mathrm{mol} \mathrm{dm} \mathrm{m}^{-3}$ ou $\mathrm{g} \mathrm{dm}^{-3}$.

$$
A_{\lambda}=\varepsilon_{\lambda} \cdot b \cdot C=\log (T)=\log \left(\frac{I_{s}}{I_{d}}\right)
$$

Equação $2^{68}$

$T$ é a transmitância do material, dado em porcentagem (\%); $I_{s}$ e $I_{d}$ estão descritos no texto.

$$
A_{\lambda}=\log \left(\frac{I_{s}}{I_{d}}\right)=\log \left(\frac{A C}{D C}\right)
$$

$I_{s}$ e $I_{d}$ estão descritos no texto; $A C$ e $D C$ são as correntes elétricas produzidas a partir das medidas de $I_{s}$ e $I_{d}$, respectivamente.

$$
R=\frac{(A C / D C)_{\lambda_{1}}}{(A C / D C)_{\lambda_{2}}}
$$

$R$ é a correlação entre os sinais diastólicos e sistólicos obtidos a partir de medidas em indivíduos saudáveis; $\lambda_{1} \mathrm{e}$ $\lambda_{2}$ são os comprimentos de onda (em $\mathrm{nm}$ ) escolhidos para a medida (Figura 9B).

$$
\mathrm{SaO}_{2} \cong \mathrm{SpO}_{2}=\frac{k_{1}-k_{2} R}{k_{3}-k_{4} R}
$$

$\mathrm{SaO}_{2}$ é a saturação de oxigênio arterial, medida por gasometria; $k_{1}, k_{2}, k_{3}$ e $k_{4}$ são as constantes empregadas para a calibração do oxímetro, obtidas por análise matemática a partir das medidas experimentais.

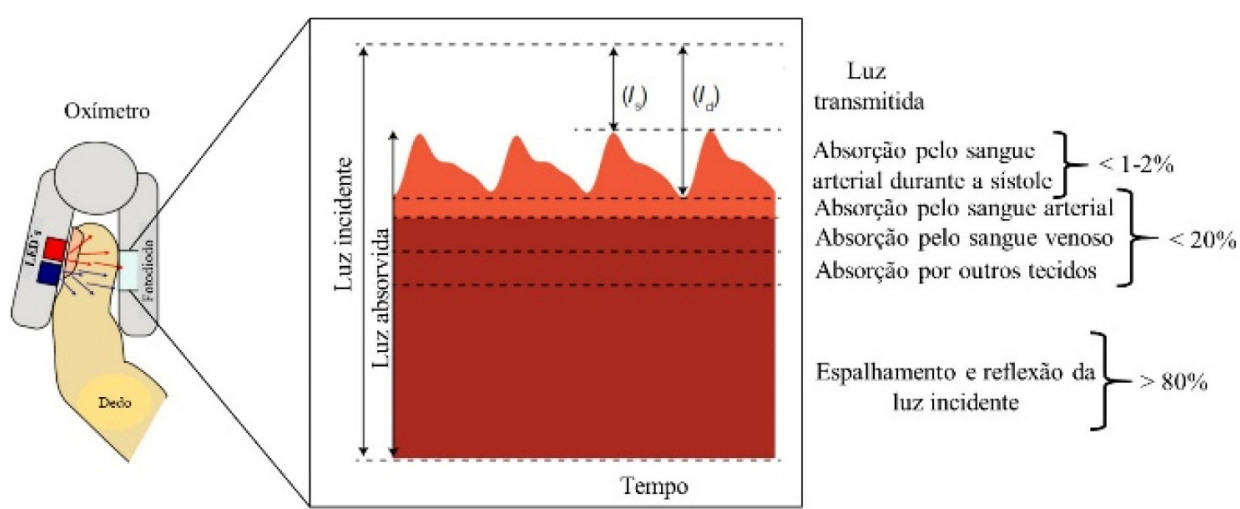

Figura 10. Esquerda: Oxímetro de dedo (na forma de um grampo) com ofotodiodo (detector) do lado oposto ao emissor de luz (LED); Direita: Fotopletismograma mostrando o perfil de absorção de luz em uma medida oximétrica durante a sístole $\left(I_{s}\right)$ e diástole $\left(I_{d}\right)$ nas fases cardíacas. Adaptado de Kyriacou e colaboradores ${ }^{65}$ 
evitar resultados errôneos. A Figura 9B mostra que em $\lambda=660 \mathrm{~nm}$ a forma $\mathrm{Hb}$ possui absorção máxima e em $\lambda=940 \mathrm{~nm}$, a absorção é predominante para a forma $\mathrm{HbO}_{2}$. Radiação eletromagnética em comprimentos de onda menores que $660 \mathrm{~nm}$ pode ser absorvida por tecidos (pele) e acima de $940 \mathrm{~nm}$, há uma forte absorção de luz pela molécula de água. Assim, a relação (R) entre as absorções nos dois comprimentos resulta na Equação 6 (Quadro 2).

Essa relação $(\mathrm{R})$ e o teor de saturação de oxigênio $\left(\mathrm{SaO}_{2}\right)$ não estão conectados diretamente a partir da análise da Lei de LambertBeer, pois há uma série de interferências que impedem uma conexão direta ${ }^{68}$ A relação entre $\mathrm{R}$ e $\mathrm{SaO}_{2}$ é determinada experimentalmente para cada tipo de oxímetro através de calibração. O parâmetro R é medido em um conjunto de voluntários saudáveis, concomitantemente com a medida de $\mathrm{SaO}_{2}$ por co-oximetria. Após tratamento matemático, a relação entre $\mathrm{R} \mathrm{e} \mathrm{SaO}_{2}$ resulta na Equação 7 (Quadro 2).

\section{CONSIDERAÇÕES FINAIS}

Dois aspectos se destacam no panorama do oxigênio no contexto da pandemia da COVID-19. O primeiro é que o Brasil domina a tecnologia de produção criogênica de oxigênio hospitalar e tem um sistema de distribuição consolidado que atende à demanda normal. Todavia, a crise do abastecimento revelou que se faz necessário ter capacidade de produção maior que a atual para atender altas efêmeras de consumo, e precisa aprimorar a distribuição dessa capacidade instalada em todo país mediante adequado planejamento, e compreender as necessidades reais durante um fenômeno de crise, pois há alternativas menos dispendiosas e mais rápidas que a produção criogênica - como a aquisição de concentradores de oxigênio que podem ser estratégicos durante um cenário atípico. Essa análise permite uma ação mais célere por parte das entidades públicas de saúde, bem como uma gestão mais adequada dos recursos financeiros.

$\mathrm{O}$ segundo aspecto diz respeito à química como ciência central nas medidas de combate e mitigação da pandemia, que envolve conhecimentos sofisticados da química de substâncias estruturalmente complexas, como os presentes no reposicionamento de fármacos, cujas estruturas químicas só podem ser lidas e interpretadas por um profissional da área, e no desenvolvimento de vacinas nas quais a química está presente, entre outros aspectos, na compreensão das interações entre os constituintes das vacinas e as moléculas receptores presentes no organismo. Todavia, conhecimentos clássicos ensinados na graduação também estão envolvidos, como os presentes na produção de materiais para máscaras e protetores faciais, na produção de agentes sanitizantes (sabões, detergentes, soluções de sais quarternários de amônio, soluções alcoólicas $70 \%$ e álcool em gel), e mesmo na produção de uma substância tão simples, elementar e natural como a molécula do gás oxigênio, mas essencial no contexto da pandemia da COVID-19.

Da ciência básica à engenharia, fica evidente o papel da química como ciência central e pluridisciplinar para atender demandas em saúde pública, sendo necessário um contínuo investimento nesse campo do saber tão primordial para o desenvolvimento da sociedade e que tanto contribui para o bem-estar da humanidade.

\section{AGRADECIMENTOS}

Os autores agradecem o suporte financeiro do Conselho Nacional de Desenvolvimento Científico e Tecnológico - CNPq, da Fundação de Amparo à Pesquisa do Estado da Bahia - FAPESB e da Coordenação de Aperfeiçoamento de Pessoal de Nível Superior - Brasil (CAPES) - Código de Financiamento 001. Agradecemos as bolsas de pós-graduação do CNPq para B.C. Cerqueira e R. Campos, e a bolsa de produtividade em pesquisa de $\mathrm{S}$. Cunha.

\section{REFERÊNCIAS}

1. https://amazoniareal.com.br/caos-na-pandemia-sem-oxigenio-pacientesmorrem-asfixiados-em-manaus/, acessada em julho 2021.

2. https://amazonasatual.com.br/variante-do-coronavirus-atinge-o-peru-epais-comeca-a-enfrentar-falta-de-oxigenio/, acessada em julho 2021.

3. https://coronavirus.atarde.com.br/mp-pede-a-sesab-informacoes-sobreo-abastecimento-de-oxigenio-na-bahia/, acessada em julho 2021.

4. https://www1.folha.uol.com.br/equilibrioesaude/2021/04/pais-tem-maisde-mil-cidades-com-dificuldades-no-abastecimento-de-oxigenio.shtml, acessada em julho 2021 .

5. https://agenciabrasil.ebc.com.br/saude/noticia/202-19-por-falta-deoxigenio, acessada em julho 2021.

6. https://www.cartacapital.com.br/saude/entenda-como-funciona-ofornecimento-de-oxigenio-a-pacientes-com-covid/, acessada em julho 2021.

7. https://www.saopaulo.sp.gov.br/noticias-coronavirus/governo-distribui624-concentradores-de-oxigenio-para-unidades-hospitalares-do-estado/, acessada em julho 2021.

8. https://www.gazetadopovo.com.br/republica/coronavirus-manauscolapso-falta-oxigenio/, acessada em julho 2021.

9. https://semsa.manaus.am.gov.br/noticia/prefeito-afirma-que-municipioconseguira-manter-oxigenio-em-seus-servicos/, acessada em julho 2021.

10. https://oglobo.globo.com/epoca/covid-em-manaus-sem-oxigeniopacientes-dependem-de-ventilacao-manual-para-sobreviver-emmanaus-24839864, acessada em julho 2021.

11. https://agenciabrasil.ebc.com.br/saude/noticia/2021-03/capacidade-deproducao-de-oxigenio-por-empresas-aumentou-ate-200\%, acessada em julho 2021.

12. https://agenciabrasil.ebc.com.br/saude/noticia/2021-03/anvisa-publicana-internet-dados-sobre-disponibilidade-de-oxigenio, acessada em julho 2021.

13. https://agenciabrasil.ebc.com.br/saude/noticia/2021-03/capacidade-deproducao-de-oxigenio-por-empresas-aumentou-ate-200, acessada em julho 2021.

14. https://agenciabrasil.ebc.com.br/saude/noticia/2021-03/anvisa-publicana-internet-dados-sobre-disponibilidade-de-oxigenio, acessada em julho 2021.

15. https://www.gov.br/saude/pt-br/assuntos/noticias/plano-oxigenio-brasilsaude-coordena-acoes-de-apoio-a-estados-e-municipios, acessada em julho 2021.

16. https://agenciabrasil.ebc.com.br/saude/noticia/2021-03/estoques-deoxigenio-estao-em-nivel-critico-em-municipios-paulistas, acessada em julho 2021.

17. Brasil; Medida provisória N ${ }^{\circ} 1.033$, DE 24 de Fevereiro 2021. Altera a Lei $\mathrm{n}^{\circ} 11.508$, de 20 de julho de 2007, que dispõe sobre o regime tributário, cambial e administrativo das Zonas de Processamento de Exportação, para conceder tratamento à produção de oxigênio. Diário Oficial da União, p. 5.

18. Brasil; Lei No 11.508 , de 20 de Julho de 2007. Dispõe sobre o regime tributário, cambial e administrativo das Zonas de Processamento de Exportação, e dá outras providências. Diário Oficial da União, p. 2.

19. Toma, H. E.; Quim. Nova 2019, 42, 468.

20. Morgon, N.; Freitas, R.; Quim. Nova 2019, 42, 1123.

21. Silva, L. A.; Victor, M. M.; Lopes, W. A.; Cunha, S.; Quim. Nova 2019, 42, 1154

22. Lima, M.; Almeida, R.; Fonseca, F.; Gonçalves, C.; Lima, M. L. S. O.; Almeida, R. K. S.; da Fonseca, F. S. A.; Gonçalves, C. C. S.; Quim. Nova 2020, 43, 668.

23. Sequinel, R.; Lenz, G. F.; da Silva, F. J. L. B.; da Silva, F. R.; Quim. Nova 2020, 43, 679.

24. Lima, M.; Felix, E.; Cardoso, A.; Quim. Nova (2021), doi: 10.21577/0100-4042.20170759. 
25. Haynes, W. M.; Lide, D. R.; Bruno, T. J.; Handbook of Chemistry and Physics; $95^{\text {th }}$ ed., CRC Press: New York.

26. Greenwood, N. N.; Earnshaw, A.; Chemistry of the Elements; $2^{\text {nd }}$ ed.; Butterworth Heinemann: Oxford, 1997.

27. Martins, C. R.; Pereira, P. A. P.; Lopes, W. A.; de Andrade, J. B.; QNESc 2003, 5, 28.

28. Filgueiras, C. A. L.; Lavoisier. O Estabelecimento da Química Moderna - Coleção Imortais da Ciência; Odysseus Editora: São Paulo, 2002.

29. Nyasulu, F.; Macklin, J.; Cusworth, W.; J. Chem. Educ. 2002, 79, 356.

30. Tudela, D.; Fernández, V.; J. Chem. Educ. 2003, 80, 1381.

31. Douglas, B.; McDaniel, D.; Alexander, J.; Concepts and Models of Inorganic Chemistry; $3^{\text {rd }}$ ed.; John Wiley \& Sons, Inc.: New York, 1994.

32. Shriver, D. F.; Atkins, P. W.; Overton, T. L.; Rourke, J. P.; Weller, M. T.; Armstrong, F. A.; Shriver \& Atkins: Química Inorgânica; $4^{\mathrm{a}}$ ed.; Bookman: Porto Alegre, 2008.

33. Lee, J. D.; Química Inorgânica não tão concisa, Edgard Blücher: São Paulo, 1999

34. Silva, L. A.; de Andrade, J. B.; Lopes, W. A.; Carvalho, L. S.; Pereira, P. A. P.; Silva, L. A.; Quim. Nova 2017, 40, 824.

35. Huheey, J. E.; Keiter, E. A.; Keiter, R. L.; Inorganic Chemistry Principles of Structure and Reactivity; $4^{\text {th }}$ ed.; Harper Collins: New York, 1993.

36. Rodríguez González-Moro, J. M.; Bravo Quiroga, L.; Alcázar Navarrete, B.; Alfageme Michavila, I.; Díaz Lobato, S.; Open Respiratory Archives 2020, 2, 33 .

37. Ortega Ruiz, F.; Díaz Lobato, S.; Galdiz Iturri, J. B.; García Rio, F.; Güell Rous, R.; Morante Velez, F.; Puente Maestu, L.; Tàrrega Camarasa, J.; Archivos de Bronconeumología 2014, 50, 185.

38. https://www.gov.br/anvisa/pt-br/setorregulado/regularizacao/ medicamentos/gases-medicinais/gases-medicinais-informacoes-gerais, acessada em julho 2021 .

39. Fernández Abásolo, A.; Revista Oficial de la Sociedad Andaluza de Farmacéuticos de Hospitales 2005, vol 1.

40. Brasil; Diário Oficial da União, 2019.

41. https://www.gov.br/anvisa/pt-br/assuntos/noticias-anvisa/2021/anvisalibera-producao-de-oxigenio-a-95-de-teor/nota-tecnica-o2-medicinal. pdf, acessada em julho 2021.

42. Smith, A. R.; Klosek, J.; Fuel Process. Technol. 2001, 70, 115.

43. Kerry, F. G.; Industrial gas handbook: gas separation and purification; CRC Press: Boca Raton, 2007.

44. Bengtsson, L.; Environ. Res. Lett. 2010, 5, 025202.

45. Downie, N. A.; Industrial gases; Springer Science \& Business Media: New York, 2007.

46. Leite, V. O.; Trabalho de Conclusão de Curso, Universidade de São Paulo, Brasil, 2006.

47. Chai, S. W.; Kothare, M. V.; Sircar, S.; Ind. Eng. Chem. Res. 2011, 50, 8703.

48. Ferreira, D.; Bárcia, P.; Whitley, R. D.; Mendes, A.; Ind. Eng. Chem. Res. 2015, 54, 9591.

49. Sircar, S.; Kratz, W. C.; Sep. Sci. Technol. 1989, $24,429$.

50. Atkins, P. W.; de Paula, J.; Physical Chemistry, ${ }^{\text {th }}$ ed., Oxford University Press: New Jersey, USA, 2010.
51. Yang, R. T.; Adsorbents: fundamentals and applications; John Wiley \& Sons, Ltd: New Jersey, USA, 2003.

52. Chao, C. C.; EP 0297542 A2 1989.

53. Ackley, M. W.; Adsorption 2019, 25, 1437.

54. https://acobrasil.org.br/site/wp-content/uploads/2020/04/Mini_ anuario_2020_completo.pdf, acessada em julho 2021.

55. Rossi, D.; Dissertação de Mestrado, Universidade Federal do Rio Grande do Sul, Brasil, 2014.

56. https://www.praxair.com.br/-/media/corporate/praxair-brazil/documents/ specialty-gases/vimpressa--catlogo-ge--miolo--ago_2013--layout-02-pgs-independentes.pdf?la=pt-br, acessada em julho 2021.

57. https://www.praxair.com.br/gases/buy-liquid-oxygen-or-compressedoxygen-gas, acessada em julho 2021.

58. Brasil; Saúde prepara distribuição de mais de 5 mil concentradores de oxigênio, disponível em https://www.gov.br/saude/pt-br/assuntos/ noticias/saude-prepara-distribuicao-de-mais-de-5-mil-concentradoresde-oxigenio, acessada em julho 2021.

59. Wunsch, H.; Am. J. Respir. Crit. Care Med. 2020, $202,1$.

60. Dhont, S.; Derom, E.; Van Braeckel, E.; Depuydt, P.; Lambrecht, B. N.; Respir. Res. 2020, 21, 198.

61. Luks, A. M.; Swenson, E. R.; Ann. Am. Thorac. Soc. 2020, 17, 1040.

62. Nunes, W. A.; Terzi, R. G. G.; Rev. Lat. Am. Enfermagem 1999, 7, 79.

63. Herrmann, J.; Mori, V.; Bates, J. H. T.; Suki, B.; Nat. Commun. 2020, 11,1 .

64. Steppan, J.; Hogue, C. W.; Best Pract. Res., Clin. Anaesthesiol. 2014, $28,429$.

65. Kyriacou, P.; Budidha, K.; Abay, T. Y.; In Encyclopedia of Biomedical Engineering; Narayan, R., ed.; Elsevier: Amsterdam, 2019; Vol. 1-3, pp. 461-472.

66. Matthews, B.; J. Paramed. Pract. 2018, 10, 126.

67. Thawley, V.; Waddell, L. S.; Topics in Companion Animal Medicine 2013, 28, 124.

68. Nitzan, M.; Romem, A.; Koppel, R.; Med. Devices: Evidence Res. 2014, 7, 231.

69. PDB, R.; RCSB PDB - 3A0G: Crystal structure analysis of oxyhemoglobin, https://www.rcsb.org/structure/3A0G, acessada em julho 2021.

70. PDB, R.; RCSB PDB - 2H35: Solution structure of hemoglobin, https:// www.rcsb.org/structure/2h35, acessada em julho 2021.

71. Berman, H.; Henrick, K.; Nakamura, H.; Nat. Struct. Mol. Biol. 2003, 10,980.

72. Symons, R.; Chatterji, R.; Whenan, K.; Horvath, R.; Thomas, P. S.; In Encyclopedia of Biomedical Engineering; Narayan, R., ed.; Elsevier: Amsterdam, 2019; Vol. 1-3, pp. 305-316.

73. Mildenhall, J. L.; J. Paramed. Pract. 2008, 1, 52.

74. Kaufman, D. P.; Dhamoon, A. S.; Physiology, Oxyhemoglobin Dissociation Curve; StatPearls Publishing: Treasure Island, 2019.

75. Chan, E. D.; Chan, M. M.; Chan, M. M.; Respir. Med. 2013, 107, 789.

76. Prahl, S.; Optical Absorption of Hemoglobin, disponível em https://omlc. org/spectra/hemoglobin/, acessada em julho 2021. 